\title{
Triple Negative Breast Cancer-derived Small Extracellular Vesicles as Modulator of Biomechanics in target cells
}

\section{Short title: small EVs as modulator of cell biomechanics}

\author{
Beatrice Senigagliesi ${ }^{1,2}$, Giuseppe Samperi ${ }^{3}$, Nicola Cefarin ${ }^{4}$, Luciana Gneo ${ }^{5}$, Sara Petrosino ${ }^{6}$, \\ Mattia Apollonio ${ }^{7}$, Federica Caponnetto ${ }^{8}$, Riccardo Sgarra ${ }^{7}$, Licio Collavin ${ }^{7}$, Daniela Cesselli ${ }^{8}$, \\ Loredana Casalis $^{2} *$, Pietro Parisse ${ }^{2,4} *$
}

\author{
1 Scuola Internazionale Superiore di Studi Avanzati, 34127 Trieste, Italy; \\ beatrice.senigagliesi@sissa.it/beatric.senigagliesi@gmail.com; \\ 2 Elettra-Sincrotrone Trieste S.C.p.A., Trieste, Italy; loredana.casalis@elettra.eu; \\ 3 University of Parma; giuseppe.samperi@studenti.unipr.it \\ 4 Istituto Officina dei Materiali Consiglio Nazionale delle Ricerche, TASC, Trieste, Italy; nicolacefa@ gmail.com; \\ parisse@iom.cnr.it; \\ 5 University of Oxford; Oxford OXI 2JD, GB; luciana.gneo@well.ox.ac.uk; \\ 6 Telethon Institute of Genetics and Medicine, Naples, Italy; s.petrosino@ tigem.it; \\ 7 Department of Life Science, University of Trieste, 34127 Trieste, Italy; rsgarra@units.it; apollonio.mattia@hotmail.it; \\ lcollavin@units.it; \\ 8 Pathology Department, University Hospital of Udine, P.le S. Maria della Misericordia, 33100 Udine (UD), Italy; \\ the_capo@hotmail.com; daniela.cesselli@uniud.it;
}

\section{*Corresponding authors: Loredana.casalis@elettra.eu (L.Ca.); parisse@iom.cnr.it (P.P.)}

\begin{abstract}
Extracellular vesicle (EV) mediated communication has recently been proposed as one of the pivotal routes in the development of cancer metastasis. EVs are nano-sized vesicles swapped between cells, carrying a biologically active content that can promote tumor-induced immune suppression, metastasis and angiogenesis. Thus, EVs constitute a potential target in cancer therapy. However, their role in triggering the premetastatic niche and in tumor spreading is still unclear. Here, we focused on the EV ability to modulate the biomechanical properties of target cells, known to play a crucial role in metastatic spreading. To this purpose, we isolated and thoroughly characterized triple-negative breast cancer (TNBC)-derived small EVs. We then evaluated variations in the mechanical properties (cell stiffness, cytoskeleton/nuclear/morphology and Yap activity rearrangements) of non-metastatic breast cancer MCF7 cells upon EV treatment. Our results suggest that TNBC-derived small EVs are able to directly modify MCF7 cells by inducing a decrease in cell stiffness, rearrangements in cytoskeleton, focal adhesions and nuclear/cellular morphology, and an increase in Yap downstream gene expression. Testing the biomechanical response of cells after EV addition might represent a new functional assay in metastatic cancer framework that can be exploited for future application both in diagnosis and in therapy.
\end{abstract}

\section{Keywords: Extracellular Vesicles, Breast Cancer, Biomechanics}

Word count: Abstract 198, Manuscript 6613. Number of references 68. Number of figures 8. 


\section{INTRODUCTION}

Breast Cancer is the most frequently diagnosed malignancy and stands as the leading cause of cancer mortality in women worldwide (Momenimovahed \& Salehiniya, 2019). Triple-negative breast cancer (TNBC), in particular, is the most aggressive breast cancer subtypes and with a poor prognosis due to the absence of targetable receptors, such as estrogen receptor (ER), progesterone receptor (PR) and epidermal growth factor receptor-2 (HER2), and to the high propensity for metastatic progression (Yeo, 2015). Nowadays, chemotherapy is the main treatment in both early and advanced stage of TNBC (Shang et al., 2018). Unfortunately, approximately $80 \%$ of TNBC patients show an incomplete response to conventional chemotherapy, disease recurrence, and metastasis formation after surgery (Jhan \& Andrechek, 2017; Nakashoji et al., 2017). Therefore, shedding light on the biological mechanisms of the metastatic progression in TNBC is urgent to track down novel therapeutic approaches for effective interventions (Yao et al., 2021). The development of metastasis requires a series of stages that lead to the formation of secondary tumor sites in distant organs: metastatic cancer cells leave the primary site, pass through the basement membrane and extracellular matrix (invasion process), penetrate and survive in lymphatic or vascular circulation (intravasation), leave vessels (extravasation), and ultimately create pre-metastatic niche for the formation of the secondary tumor sites (Martin et al., 2014; Shibue \& Weinberg, 2017). Nowadays, the capacity of cancer cells to undergo different phenotypic changes is well recognized.

The recent literature has provided evidences for a direct correlation between the metastatic potential of cancer cells and their biomechanical properties: deformable, softer cancer cells can migrate more easily through the narrow pores of the matrix and vessels boosting the processes of invasion, intravasation, and extravasation (Alibert et al., 2017; Lekka, 2016; Q. Luo et al., 2016). However, the specific nature of these mechanisms remains to be understood. In fact, cell biomechanical changes include complex transformations at the level of nucleus, cytoskeleton, and plasma membrane that are due to the mutual interaction with the extracellular microenvironment (Alibert et al., 2017; Lüchtefeld et al., 2020). On the other hand cell motility, to which the metastatic potential of cancer cells is directly related, depends on the bidirectional interplay between actin and microtubule organization and expression, and several cytoskeletal regulators (Dogterom \& Koenderink, 2019; Etienne-Manneville, 2004). The cancer community has recently also emphasized the role of the tumor-secreted extracellular vesicle (EVs) in the regulation of tumor progression and metastasis (Bao et al., 2021; Becker et al., 2016). EVs are nano-sized particles delimited by a lipid bilayer, capable of transferring functional cargos (e.g. proteins, nucleic acids, and lipids) from donor to target cells, in which they activate combinatorial effects (Tschuschke et al., 2020). Since different tissues and organs throughout the body release EVs, analysis of EVs could give useful information in the early diagnosis, progression, and therapy monitoring of diseases (Boukouris \& Mathivanan, 2015; Kalluri \& LeBleu, 2020). Moreover, being released in the extracellular space, EVs can be detected non-invasively in body fluids (Boukouris \& Mathivanan, 2015). According to the vast majority of the EV community, vesicles are divided into two big classes, "small EVs" (sEVs) and "medium/large EVs" (m/lEVs), with dimensions < $200 \mathrm{~nm}$ and > $200 \mathrm{~nm}$, respectively (Thery et al., 2018). M/lEVs are mainly formed by the direct outward budding of the cellular 
plasma membrane (Cai et al., 2007), while sEVs have usually an endocytic origin (Bebelman et al., 2018). The involvement of EVs in tumor-tumor and tumor-stromal cell (non-malignant cells that surround the primary tumor) communication of both primary tumor progression and metastasis formation has been documented (Becker et al., 2016; Chen et al., 2017; Maacha et al., 2019). Concerning TNBC, it has been shown that TNBC cells can transfer oncogenic proteins, mRNAs, and miRNAs to target cells through EVs by promoting metastatic spreading and pre-metastatic niche formation (Green et al., 2015). Although EVs are known to be the main putative agents at the base of these processes (Ozawa et al., 2018; Peng et al., 2018), further attention is still needed to grasp the mechanisms through which they operate. Understanding the ways EVs deliver their cargo and affecting host cells properties is crucial to ultimately exploit them as novel therapeutic vehicles (Bahreyni et al., 2020). In particular, there is evidence that small extracellular vesicles (small EVs) are involved in modulation of cellular signaling pathways and metabolic state of target cells (Maia et al., 2018). Yet, to our knowledge, the role played by the small EVs in the modulation of recipient cell biomechanics has been poorly investigated. Here, we focused on the isolation and characterization of TNBC-derived small EVs and on the analysis of the phenotype changes they induce in non-metastatic target cells. We demonstrate for the first time a direct involvement of small EVs in the modulation of cytoskeleton, adhesion, nuclear/cellular morphology, and, as a consequence, on the biomechanical properties of the entire cells. Our findings might open new routes for the diagnosis and future therapy of this aggressive, targetorphan breast cancer subtype (Goh et al., 2020), as well as new insights into EV activity. Such findings could also be extended to other classes of EVs or to other diseases, where biomechanical properties play a crucial role (Lee \& Lim, 2007).

\section{MATERIALS AND METHODS}

\subsection{Small Extracellular Vesicles Isolation}

\subsubsection{Cell cultures and experimental conditions for small extracellular vesicle isolation}

MCF7 and MDA-MB-231 breast cancer cell lines were cultivated in DMEM (Dulbecco's Modified Eagle's Medium High Glucose with Sodium Pyruvate with L-Glutamine, EuroClone, ECM0728L) supplemented with 10\% FBS (Fetal Bovine Serum South America origin EU, EuroClone, ECS0180L) and 1\% Penicillin/Streptomicin (100X, EuroClone, ECB3001D). Cell lines were grown at $37^{\circ} \mathrm{C}$ in humidified $5 \%$ $\mathrm{CO}_{2}$ incubator and split every 2-3 days according to their confluence. The culture and harvesting conditions, such as passage number and seeding confluence, were maintained the same and regular checks for Mycoplasma contamination were performed on cells for vesicle isolation.

\subsubsection{Small Extracellular vesicle isolation by ultracentrifuge}

MDA-MB-231 cells $\left(2.5 \times 10^{6}\right)$ were grown in $175 \mathrm{~cm}^{2}$ flask in DMEM with $10 \%$ FBS for 2-3 days in order to avoid cellular stress; after that the cells were washed twice with PBS and, then, three times with DMEM without FBS to reduce the presence of serum contaminants (e.g. serum vesicles, albumin, RNA or proteins). After 24h in DMEM without FBS the small EVs were collected. The supernatant was centrifuged at $300 \mathrm{~g}$ 
for 10 minutes at $4^{\circ} \mathrm{C}$ to pellet cells and cell debris. The resulting supernatant was filtered using a $0.2 \mu \mathrm{m}$ filter to remove the medium/large EVs, big circulating proteins and cell debris. The filtered supernatant was transferred into Amicon Ultra-15 centrifugal filters (Ultracel-PL PLHK, 100kDa cutoff, Merck Millipore, UFC9100) and centrifuged at $4,000 \mathrm{~g}$ for 40 minutes at $4{ }^{\circ} \mathrm{C}$, in order to concentrate the medium to use the ultracentrifuge tubes with a reduced volume capacity for the small EV isolation $(8.9 \mathrm{ml}$ polypropylene centrifuge tube, Beckman Coulter, 361623). The tubes were filled with PBS to reach the final volume and samples were ultracentrifuged at $120,000 \mathrm{~g}$ for 60 minutes at $4^{\circ} \mathrm{C}(70.1 \mathrm{Ti}$ rotor, k-factor 36 , Beckman Coulter, Brea, CA, USA). Finally, the supernatant was removed, the pellet resuspended in PBS, and small EVs were stored at $-20^{\circ} \mathrm{C}$ for short term periods.

\subsection{Small Extracellular Vesicles Characterization}

\subsubsection{Scanning Electron Microscopy}

Scanning Electron Microscopy (SEM) images were acquired with a Zeiss Supra40 SEM. Imaging was performed at low acceleration voltage $(5 \mathrm{keV})$ by detecting secondary electrons. The silica slide was cleaned with acetone and isopropanol and a drop of Poly-L-Lysine (Sigma-Aldrich) was added, in order to facilitate the capture of small EVs via electrostatic interactions. Subsequently, the excess of Poly-L-Lysine was removed by performing two washes with $\mathrm{H}_{2} \mathrm{O}$ Milli-Q. Then, $10 \mu \mathrm{L}$ of small EVs were spotted on the treated silica slide. The vesicles were mixed directly on the silica slide with an equal volume of $5 \%$ glutaraldehyde solution prepared in PBS to allow the vesicle fixation. The mixture was incubated for 30 minutes. The sample was washed and dehydrated with increasing ethanol solution, until it dried at room temperature. PBS was used as negative control. Before the scanning, sample was sputter-coated with a thin layer of $\mathrm{Au} / \mathrm{Pd}$ (thickness of approximately $5 \mathrm{~nm}$ ) to assure conductivity. For each sample, 10 different areas of $\sim 14 \mu \mathrm{m} \mathrm{x}$ $10 \mu \mathrm{m}$ were imaged. SEM images were analyzed with Gwyddion ${ }^{\circledR}$ software (Nečas \& Klapetek, 2012). Vesicle diameters were obtained by applying a threshold to the images and then evaluating the grain distributions.

\subsubsection{Atomic Force Microscopy}

Atomic Force Microscopy (AFM) images were acquired using a commercially available microscope (MFP3D Stand Alone AFM from Asylum Research, Santa Barbara, CA). Measurements were carried out at room temperature working in dynamic AC-mode. Commercially available silicon cantilevers (BL-AC40TS-C2, Olympus Micro Cantilevers, nominal spring constant $0.09 \mathrm{~N} \mathrm{~m}-1$ and resonant frequency $110 \mathrm{kHz}$ ) have been chosen for imaging in liquid. For the AFM imaging of the small EVs, a freshly cleaved muscovite mica sheet (Ruby Muscovite Mica Scratch Free Grade V-1, Nanoandmore GMBH, USA) was incubated with a drop of Poly-L-Lysine (Sigma-Aldrich) for 15 minutes at room temperature. Subsequently, the excess of Poly-L-Lysine was removed by performing two washes with $\mathrm{H}_{2} \mathrm{O}$ Milli-Q. A drop of small EV suspension was loaded to the poly-lysine-coated mica surface at room temperature for 15 minutes to allow vesicles to bind the surface via electrostatic interactions. The PBS was used as negative control. For each sample, 5 
images with $10 \mu \mathrm{m} \times 10 \mu \mathrm{m}$ of scan size and with a resolution of $1024 \times 1024$ pixels (pixel size $\sim 10 \mathrm{~nm} \times$ $10 \mathrm{~nm}$ ) were acquired. The AFM images were analyzed with the Gwyddion ${ }^{\circledR}$ software. Vesicle heights and diameters were obtained by applying to the images a threshold of $10 \mathrm{~nm}$ in height and evaluating, then, the grain distributions of all grains higher than $10 \mathrm{~nm}$.

\subsubsection{Nanoparticle Tracking Analysis}

Concentration and particle size distribution of purified small EVs derived from MDA-MB-231 were obtained by Nanosight (LM10, Malvern system Ltd., U.K.), equipped with a $405 \mathrm{~nm}$ laser. Each sample, once properly diluted, was recorded for 60 seconds with a detection threshold set at maximum. Temperature was monitored throughout the measurements. Vesicle size distribution and an estimated concentration of NTA (Nanoparticle Tracking Analysis) profiles were obtained from the given raw data files.

\subsubsection{Western blot}

MDA-MB-231 cells and 231_sEVs were dissolved in SDS sample buffer (125 mM Tris/HCl pH 6.8, 4\% w/v SDS, $20 \%$ glycerol, traces of bromophenol blue and $0.2 \mathrm{M} \mathrm{DTT}$ ) and heated for 5 minutes at $96{ }^{\circ} \mathrm{C}$ (except samples for recognition of tetraspanins). Proteins were separated by SDS-polyacrylamide gel electrophoresis and transferred at $4{ }^{\circ} \mathrm{C}$ for 16 hours to a nitrocellulose membrane $(\varnothing 0.2 \mu \mathrm{m}$ GE Healthcare, Whatman, 10401396) through a wet transfer system (transfer buffer: 20\% methanol, $25 \mathrm{mM}$ Tris, $200 \mathrm{mM}$ Glycine). Membrane was stained with Red Ponceau solution (0.2\% Red Ponceau S, 3\% trichloroacetic acid, 3\% sulfosalicylic acid), incubated in agitation for 10 minutes. After blocking the membranes (5\% NFDM - nonfat dry milk (w/v) and $0.1 \%(\mathrm{v} / \mathrm{v})$ Tween 20 in PBS), blots were incubated for 1 hour at RT with primary antibodies. Incubation with horseradish peroxidase-conjugated secondary antibodies for 1 hour was performed after three washes of the membranes with blocking solution. After three final washes with blocking solution and two with PBS, chemiluminescence substrate ECL kit (Thermo Scientific, 2106) was added to the membrane in order to visualize the target proteins through Bio-Rad ChemiDoc ${ }^{\mathrm{TM}}$ Imagers. The primary antibodies used were: anti-CD63 (1:50, in native conditions, Santa Cruz Biotechnology, sc-5275), anti-Tsg 101 (1:50, Santa Cruz Biotechnology, sc-7964), anti-Calnexin (1:80, Santa Cruz Biotechnology, sc23954), and anti-Albumin (1:50, Santa Cruz Biotechnology, sc-374670).

\subsection{Functional Experiment: Small Extracellular Vesicle uptake in target cell}

\subsubsection{Bradford assay}

Protein concentration via Bradford assay was used to obtain an estimation of the quantity of small EVs for downstream application. For sample preparation, small EVs and cells were lysed in RIPA buffer in order to extract proteins. Solutions were centrifuged at $14,000 \mathrm{~g}$ for 10 minutes, recovering the supernatant, in order to eliminate cell debris. A small volume of samples (different BSA solutions and the unknown sample) was deposited on a 96-well plate. Afterwards, $200 \mu \mathrm{L}$ of Coomassie Brilliant Blue G-250 (Bradford-Solution for protein determination, EuroClone, APA69320500) was added to each sample. Incubation for 10 minutes led 
to a stable protein-dye complex that was monitored at $595 \mathrm{~nm}$ using a spectrophotometer TECAN infinite F200 PRO (Tecan Trading AG, Switzerland). The vesicle protein amount was calculated using a BSA calibration curve in a range of $0.05-2 \mathrm{mg} / \mathrm{mL}$. Each sample was analyzed in triplicate (in three different wells).

\subsubsection{Proliferation assay}

MCF7 and MDA-MB-231 cells ( $1 \times 10^{5}$ for $24 \mathrm{~h}$ and $0.5 \times 10^{5}$ cells for $48 \mathrm{~h}$ of incubation time) were seeded in a $24-w e l l$ plate and were left to grow for $24 \mathrm{~h}$. Afterwards, cells were washed and fresh culture medium containing small EVs derived from MDA-MB-231 at different concentrations $(0.5 \mu \mathrm{g} / \mu \mathrm{L}, 0.1 \mu \mathrm{g} / \mu \mathrm{L}$ and 0.2 $\mu \mathrm{g} / \mu \mathrm{L}$ ) was added. PBS was used as negative control. Each experimental condition was analyzed in triplicate (in three different wells). MCF7 cells were left to incubate with vesicles for $48 \mathrm{~h}$. Then, target cells were collected and counted.

\subsubsection{Immunofluorescence}

Immunofluorescence images were carried out using a microscope (Inverted Research Microscope Eclipse Ti, Nikon) equipped with an epi-fluorescence illuminator or a $488 \mathrm{~nm}$ laser for Total Internal Reflection Fluorescence (TIRF) application. For sample preparation, cells were fixed in $4 \%$ paraformaldehyde for 20 minutes, washed in PBS, permeabilized with 0.5\% PBS-TWEEN for 10 minutes and 0.1\% PBS-TWEEN for 5 minutes (three times). Subsequently, cells were blocked in 1\% BSA in 0.1\% PBS-TWEEN for 60 minutes. Antigen recognition was performed by incubating primary antibody in a humidified chamber for different times (Phalloidin, Invitrogen, A12381; anti-Vinculin, Invitrogen, 42H89L44; anti-pFAK, Cell signaling, 3283S) and with anti-mouse/rabbit Alexa Fluor 488-594 (Invitrogen, A11008, A11005) as secondary antibody in a humidified chamber for 60 minutes. Nuclei were stained with DAPI (Sigma Aldrich). Images were analyzed by using Image $\mathrm{J}^{\circledR}$.

\subsubsection{Force Spectroscopy Atomic Force Microscopy}

Force spectroscopy analysis of cells was carried out by using a Smena AFM (NT-MDT Co., Moscow, Russia) mounted on an inverted fluorescence microscope (Nikon Eclipse Ti-U). A silicon spherical tip with a diameter of $20 \mu \mathrm{m}$ (Tip: CSG01 cantilever from NT-MDT Smena, $\mathrm{k}=0.006-0.012 \mathrm{~N} / \mathrm{m}$ ) was used, in order to collect the global stiffness of each cell. For sample preparation, cells were fixed in $4 \%$ paraformaldehyde for 20 minutes, washed in PBS and stained with DAPI. Cells were measured in PBS buffer with $1 \%$ penicillin/streptomycin at RT. Despite PFA fixation can induce alteration in the cell stiffness (Kim et al., 2017), it is known that the relative variations stiffness after treatments remain statistically significant even after fixation (Grimm et al., 2014). Moreover, the fixation avoids the damaging due to the cell aging and it is needed for the immunofluorescence studies. For each sample, at least 30 (or 60) randomly chosen cells were measured and analyzed. Force spectroscopy measurements were performed at constant speed $(2 \mu \mathrm{m} / \mathrm{s})$, with a maximum indentation of $0.5 \mu \mathrm{m}$ and with a force applied to the sample of 1-2 $\mathrm{nN}$. Elastic modulus values 
$(\mathrm{E}, \mathrm{kPa})$ were determined by fitting the obtained force-displacement curves with Hertz model by using AtomicJ ${ }^{\circledR}$ software (Hermanowicz et al., 2014).

\subsubsection{Quantitative Real-Time Polymerase Chain Reactions}

Quantitative Real-Time PCR (RT-qPCR) technique was used to quantify gene expression of Yap downstream genes (CTGF, CYR61, and ANKRD1) in cells. Cells were lysed by TRIzol and RNA was extracted using EuroGOLD TriFast reagent (Euroclone), according to manufacturer's instructions. Purified RNA samples were quantified at Nanodrop Spectrophotometer device, by evaluating $\mathrm{ng} / \mu \mathrm{l}$ concentration, protein and phenol/ethanol contaminations. The integrity of extract material was detected analyzing the coil and supercoil strips formation. For RNA expression analysis, $0.5 \mu \mathrm{g}$ of total RNA sample $(100 \mathrm{ng} / \mu \mathrm{l})$ was retrotranscribed in stable cDNA with iScriptTM Advanced cDNA Synthesis Kit (Bio-Rad). Genes of interest were amplified with Itaq UniversSYBR Green (Bio-Rad), according to manufacturer's instructions. A CFX ConnectTM Real-Time PCR System (Bio-Rad) was used to perform Real-Time PCR. All quantitative realtime PCR (qRT-PCR) results were normalized to histone H3.

\subsubsection{Data processing and statistics}

The showed results are representative. At least 3 other independent experiments with the same trend were obtained. Data processing were performed by using Igor Pro ${ }^{\circledR}$, Origin $\mathrm{Graph}^{\circledR}$, and Microsoft Excel ${ }^{\circledR}$ software. Significance of data differences was established via two-tailed Student's t-test for immunofluorescence analyses and real-time PCR experiments and via one-way Anova for cell proliferation assay $(*=p<0.05 ; * *=p<0.01 ; * * *=p<0.001 ; * * * *=p<0.0001$, respectively). Whereas, for force spectroscopy AFM analyses the non-normally distributed Young's moduli (investigated via Shapiro-Wilk test) were compared by using the Wilcoxon test or Kruskal-Wallis one-way Anova test ${ }^{*}=p<0.05, * *=p$ $<0.01, * * *=p<0.001$ and $* * * *=p<0.0001$, respectively).

\section{RESULTS}

TNBC-derived EVs have been shown to promote proliferation and drug resistance in non-tumorigenic breast cancer (Ozawa et al., 2018) and to induce an increase in cell migration proportional to the metastatic potential of donor cells (Harris et al., 2015). Moreover, small EVs derived from breast cancer-associated stromal cells have been found to promote proliferation and migration via Hippo signaling pathway activation in non-invasive breast cancer cells (Nardone et al., 2017). Considering all this evidence, we hypothesized that small EVs might actively modulate biomechanical properties of target cells, key step in metastasis formation and progression. To test such assumption, we examined the effects of small EVs derived from the TNBC MDA-MB-231 breast cancer cells on the stiffness, cytoskeleton organization, nuclear/cellular morphology, and Yap activity of the Luminal A MCF7 breast cancer cells. The two cell lines have been chosen according to their different well-defined metastatic potential: MDA-MB-231 cells are characterized 
by high proliferation, motility, and metastatic rate (Islam \& Resat, 2017), whereas MCF7 cells are tumorigenic but have low/absent metastatic potential (Gest et al., 2013; H. et al., 2011).

\subsection{Small Extracellular Vesicle isolation and characterization}

Since the experimental conditions used for the cell growth can affect the EV recovery and the final EV sample obtained, experimental procedures were fine-tuned and standardized, as much as possible, in order to maximize the number of controlled parameters for vesicle isolation (e.g. cell culture passage number, seeding confluence, and regular checks for Mycoplasma contamination) and characterization, as suggested by MISEV2018 guidelines (Thery et al., 2018).

Small EVs were isolated from MDA-MB-231 cells by ultracentrifugation (hereinafter referred to as “231_sEVs"), as described in Materials and Methods. The isolated 231_sEVs were characterized from a morphological, dimensional, and biomolecular point of view. SEM images allowed to recognize the typical rounded structure (Figure 1a) and the small EV diameter distribution, ranging from 40 to $200 \mathrm{~nm}$ (Figure 1b), of the isolated 231_sEVs. The spherical vesicle shape of 231_EVs was confirmed also through AFM imaging (Figure 1c); also vesicle heights and diameters (from 10 to $60 \mathrm{~nm}$ and 30 to $160 \mathrm{~nm}$, respectively) derived from AFM analysis (Figure 1d) comply with those obtained in the literature (Parisse et al., 2017; Sharma et al., 2010).

NTA measurements of 231_sEVs showed a vesicle concentration of $2 \times 10^{10}$ particle/mL and a size distribution with a modal value of $\sim 150 \mathrm{~nm}$ (Figure 1e), which falls within the typical small EV diameter range (Thery et al., 2018). Western blot analysis indicated the presence of two typical small EV marker proteins: CD63 in both MDA-MB-231 cell lysate and 231_sEVs and TSG101 in cell lysate only; moreover, the analysis revealed the absence in 231_sEVs of the serum contaminant albumin and the endoplasmic reticulum-specific marker calnexin, which was detected only in MDA-MB-231 cellular lysate (Figure 1f). 


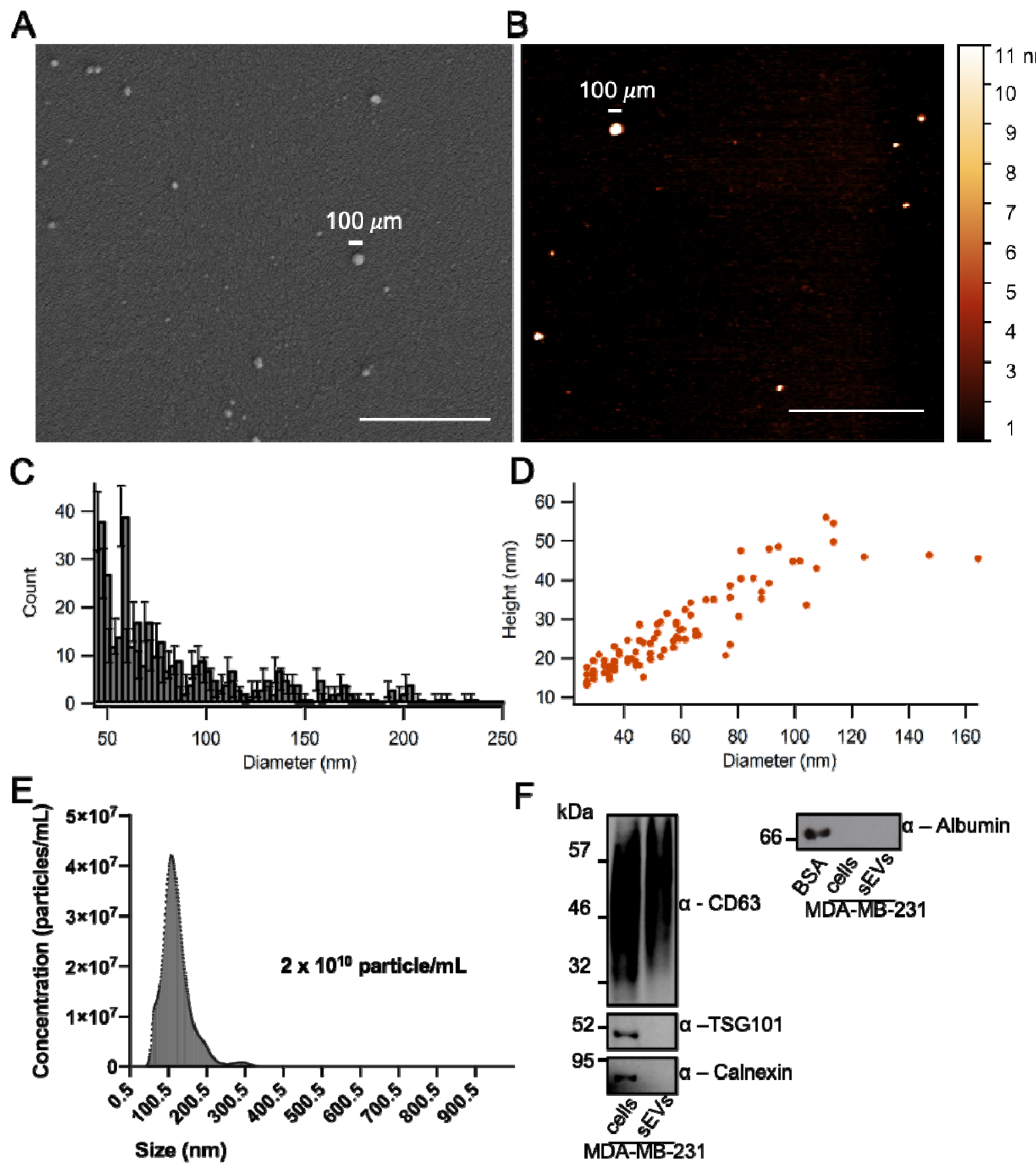

Figure 1. MDA-MB-231-derived small extracellular vesicles (231_sEVs) characterization. a) A representative SEM image of 231_sEVs. b) A representative AFM image of 231_sEVs. c) Diameter histogram of 231_sEVs obtained from the analysis of SEM images (Poisson error bars). d) Scatterplot of height and diameter vesicles obtained from the analysis of AFM images. e) Nanoparticle concentration and size distribution of 231_sEVs obtained through NTA. f) Western blot analysis of vesicle markers (CD63 and TSG101), and cellular (Calnexin) and serum (Albumin) contaminants in both MDA-MB-231 cellular lysate and 231_sEVs. Scale bar in a) and b) indicates $1 \mu \mathrm{m}$.

3.2 Functional experiments: effects of MDA-MB-231-derived small Extracellular Vesicles in MCF7 cells 
A quantitative estimation of 231_sEVs for functional experiments was performed by evaluating their protein concentration via Bradford assay (range between 0.6 and $1.1 \mu \mathrm{g} / \mu \mathrm{L}$ ). The two breast cancer cell lines, MCF7 and MDA-MB-231, have very different properties (stiffness, cytoskeleton, nuclear/cellular morphology, and Yap activity). Therefore, we decided to optimize the acquisition parameters of the experiments separately for the two cell lines and then at a later time for the MCF7 treated with 231_sEVs and MCF7 control (addition of PBS), in order to better highlight the differences between the latter two.

\subsubsection{Small Extracellular Vesicles derived from MDA-MB-231 promote proliferation in MCF7 cells}

Cell proliferation assay was first performed on MCF7 and MDA-MB-231 cells, confirming the higher proliferation of the latter, in agreement with the literature (Figure 2a) (Gest et al., 2013; H. et al., 2011; Islam \& Resat, 2017). The activity and functionality of the isolated 231_sEVs were evaluated by verifying differences in MCF7 cell proliferation upon the addition of 231_sEVs. In order to optimize cellular treatment, different vesicle concentrations $(0.05 \mu \mathrm{g} / \mu \mathrm{L}, 0.1 \mu \mathrm{g} / \mu \mathrm{L}$, and $0.2 \mu \mathrm{g} / \mu \mathrm{L})$ after 48 hours of incubation times were tested (Figure Supplementary 1). The greatest effect in proliferation was observed in the case of the highest small EV concentration, $0.2 \mu \mathrm{g} / \mu \mathrm{L}$. This condition, in comparison with the relative control, is shown in Figure 2b. No significant or lower increase in cellular proliferation was observed for all the other conditions (Figure Supplementary 1). This result indicates that isolated 231_sEVs are active and can transfer molecular information from donor to target cells.

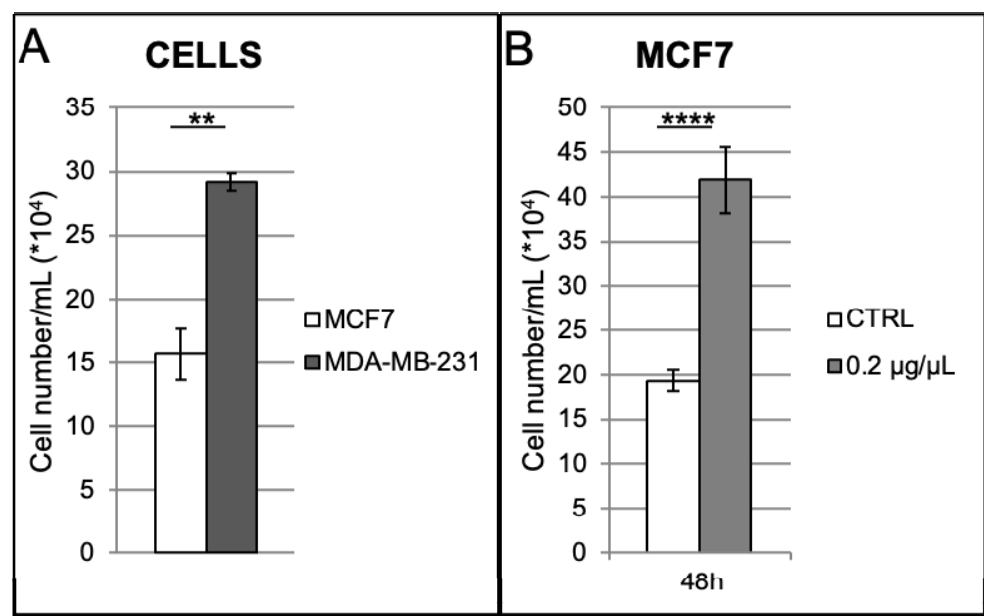

Figure 2. Effects of small EVs derived from MDA-MB-231 on MCF7 cell proliferation. a) Cell proliferation of MCF7 and MDA-MB-231 cells in comparison. b) Cell proliferation of MCF7 cells treated with 231_sEVs, in relation to their untreated control. Data are expressed as mean \pm SD. Significance of data differences was established via twotailed Student's t-test.

\subsubsection{Small Extracellular Vesicles derived from MDA-MB-231 induce biomechanical changes in MCF7 cells}


It is known from the literature that stiffness (which can be parameterized by the Young's modulus) of single cancer cells, and in particular of most metastatic ones, is lower compared to the one of healthy cells for various cancer types (Lekka, 2016). Here, we set out to evaluate if TNBC-derived small EVs can modulate cellular stiffness of recipient cells.

MCF7 and MDA-MB-231 cell stiffness was measured by means of Force Spectroscopy AFM. One forcedistance curve was acquired for each cell by indenting with a silicon spherical bead ( $20 \mu \mathrm{m}$ of diameter) up to about $10 \%(500 \mathrm{~nm})$ of the total cell height $(\sim 5 \mu \mathrm{m})$, previously measured via AFM morphological imaging (data not shown). The Young's modulus can be extracted by fitting the curve within the approximation of elastic deformation (Hertz model). As expected, the MDA-MB-231 cells resulted significantly softer than the MCF7 cells (Figure 3a). When treated with 231_sEVs at the same conditions as before, the distributions of MCF7 cell stiffness values decrease with respect to the control (Figure Supplementary 2), but only MCF7 cells treated with $0.2 \mu \mathrm{g} / \mu \mathrm{L}$ of 231_sEVs gave a significant decrease, reported in Figure 3b; two representative force-displacement curves of both MCF7 and MCF7 treated with 231_sEVs were shown in Figure 3c. To be sure that such effect is related to the specific molecular content of the 231_sEVs and not to the addition of any EVs, MCF7 cells were treated with $0.2 \mu \mathrm{g} / \mu \mathrm{L}$ of small EVs isolated from the MCF7 cells themselves (referred to as "7_sEVs"), as control. As shown in Figure Supplementary 3, no significant difference can be observed between the stiffness of MCF7 cells treated with 7_sEVs and their relative control.

Therefore, these results suggest that MDA-MB-231-derived small EVs can transfer molecular information to MCF7 target cells that is responsible for the acquisition of a biomechanical phenotype similar to donor cells.

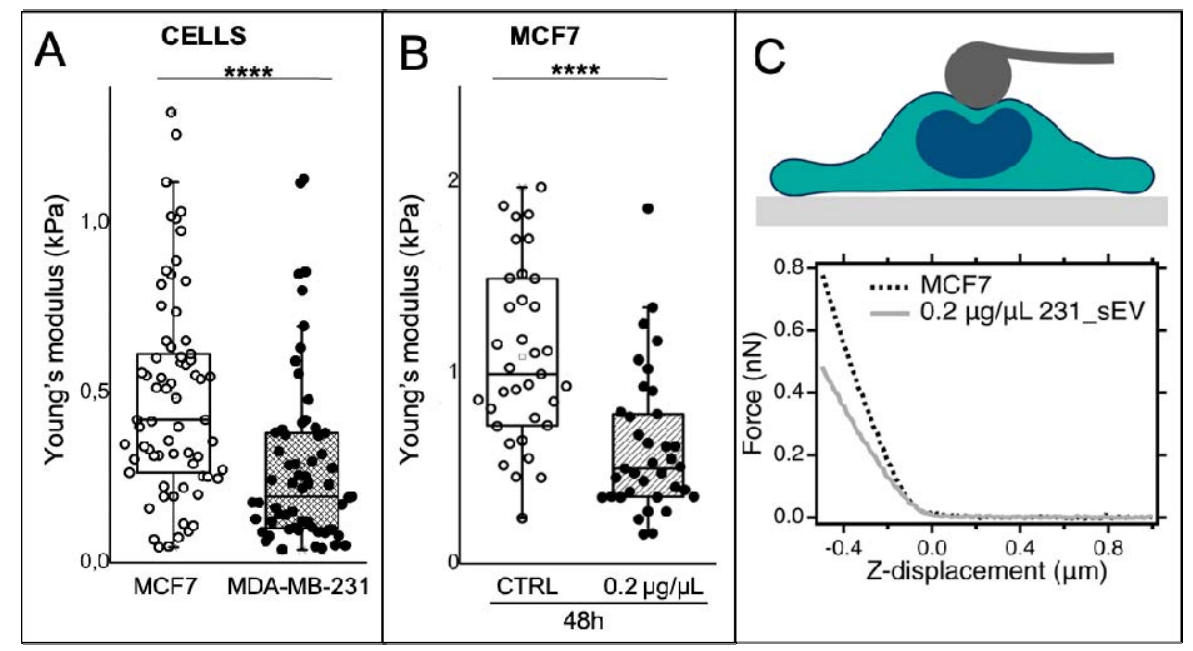

Figure 3. Effects of small EVs derived from MDA-MB-231 on the MCF7 cell stiffness. a) Boxplot showing the Young's modulus distributions of MCF7 and MDA-MB-231 single cells and b) of MCF7 cells after the addition of 231_sEVs $(0.2 \mu \mathrm{g} / \mu 1$ for 48 hours $)$, in relation to their negative control. The lower and the upper boundaries of the box represent Q1 (25 percentile) and Q3 (75 percentile) of the data, respectively; the " symbol and the horizontal bar inside the box represent the mean and median, respectively. Significance of data differences was established via Wilcoxon test. c) Representative AFM force-displacement curve of MCF7 cells and MCF7 cells upon the 231_sEV addition. 


\subsubsection{Small Extracellular Vesicles derived from MDA-MB-231 induce cytoskeleton and nuclear/cellular morphology rearrangements in MCF7 cells}

For a comprehensive understanding of the observed biomechanical changes, we explored cytoskeleton, adhesion, and nuclear/cellular morphology of MCF7 cells treated or not with 231_sEVs. Indeed, cytoskeleton organization is often associated with malignant transformation (Alibert et al., 2017) and it has important roles in cellular biomechanical modulation (Fritsch et al., 2010). Actin organization and focal adhesions (FAs) appear to play a major role in the regulation of cellular biomechanics (Tavares et al., 2017). Moreover, in cancer cells, morphology and stiffness of the nucleus, the most rigid cellular organelle, are altered when compared with healthy cells (Chiotaki et al., 2014)(Fischer et al., 2020). In particular, nuclear irregularity, deformity and softening, as result of alteration of the nucleoskeleton and nucleus-cytoskeleton interactions, are associated to high tumoral invasiveness of cancer cells (Chiotaki et al., 2014)(Senigagliesi et al., 2019). Cytoskeleton and nuclear properties of MCF7 and MDA-MB-231 breast cancer cells have already been extensively analyzed (Chiotaki et al., 2014), and turned out to be very different.

Here, significant differences were observed in F-actin (stress fibers and cortical) by comparing both the MCF7 to the MDA-MB-231 cells and the MCF7 cells treated with 231_sEVs to their control (Figure 4a-b). F-actin fluorescence intensity in both MDA-MB-231 cells and MCF7 cells after the addition of 231_sEVs resulted higher compared with the MCF7 cells and MCF7 treated with PBS (control), respectively, as shown in Figure $4(n=240$ MDA-MB-231 cells and $n=443$ MCF7 cells; $n=790$ MCF7 CTRL cells and $n=849$ 231_sEVs-treated MCF7 cells). No differences were observed in cell area of all samples taken into consideration (Figure Supplementary 4). 


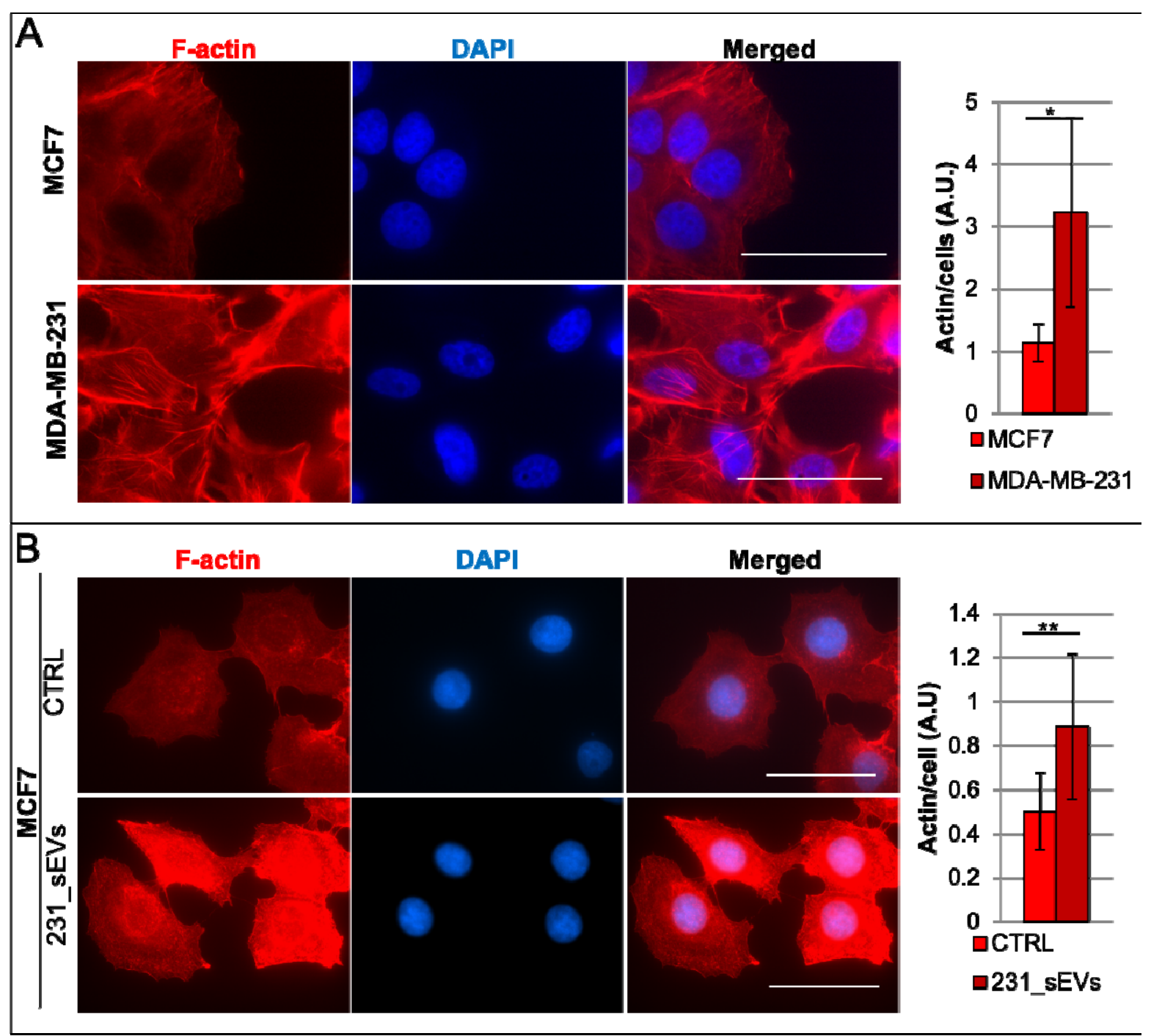

Figure 4. Effects of MDA-MB-231-derived small EVs on F-actin of MCF7 cells. Representative epifluorescence images on left and relative histograms on right, respectively, showing the F-actin of a) MCF7 and MDA-MB-231 cells and of b) MCF7 after the addition of 231_sEVs, in relation to their relative control. Data are expressed as mean \pm SD. Significance of data differences was established via two-tailed Student's t-test. Scale bar indicates $50 \mu \mathrm{m}$.

Phalloidin staining was used to assess cell shape, more specifically the elongation factor of each cell, as indicator of the spindle-like morphology of mesenchymal-like cells. The elongation factor $E$ is defined as $\mathrm{E}$ $=A_{L} / A_{S}-1$, where $A_{L}$ and $A_{S}$ represent the long and short axis of the cell, respectively. $E$ corresponds to zero for a circle, and one for an ellipse with an axis ratio 1:2. Cells that presented $E$ values $0.0-0.5$ were considered as spherical, while values equal or higher than 0.5 as elongated (Stylianou et al., 2018). MDAMB-231 cells have the typical elongated mesenchymal-like morphology compared to the MCF7 cells, as shown in epifluorescence images and relative histograms of Figure 5a $(n=24$ MDA-MB-231 cells and $n=$ 28 MCF7 cells).

When treated with 231_sEVs, MCF7 cells showed a substantial increase in the percentage of elongated cells, comnared to their control as shown in Figure $5 \mathrm{~h}(\mathrm{n}=2.5$ MCF7 CTRI, cells and $\mathrm{n}=2.52 .31$ sFV s-treated 
bioRxiv preprint doi: https://doi.org/10.1101/2022.02.28.481921; this version posted March 2, 2022. The copyright holder for this preprint (which was not certified by peer review) is the author/funder, who has granted bioRxiv a license to display the preprint in perpetuity. It is made available under aCC-BY-NC-ND 4.0 International license.

MCF7 cells). This rearrangement in shape makes the MCF7 cell morphology similar to that of MDA-MB231 cells and strongly suggests an epithelial-mesenchymal transition phenomenon, due to the 231_sEV activity.

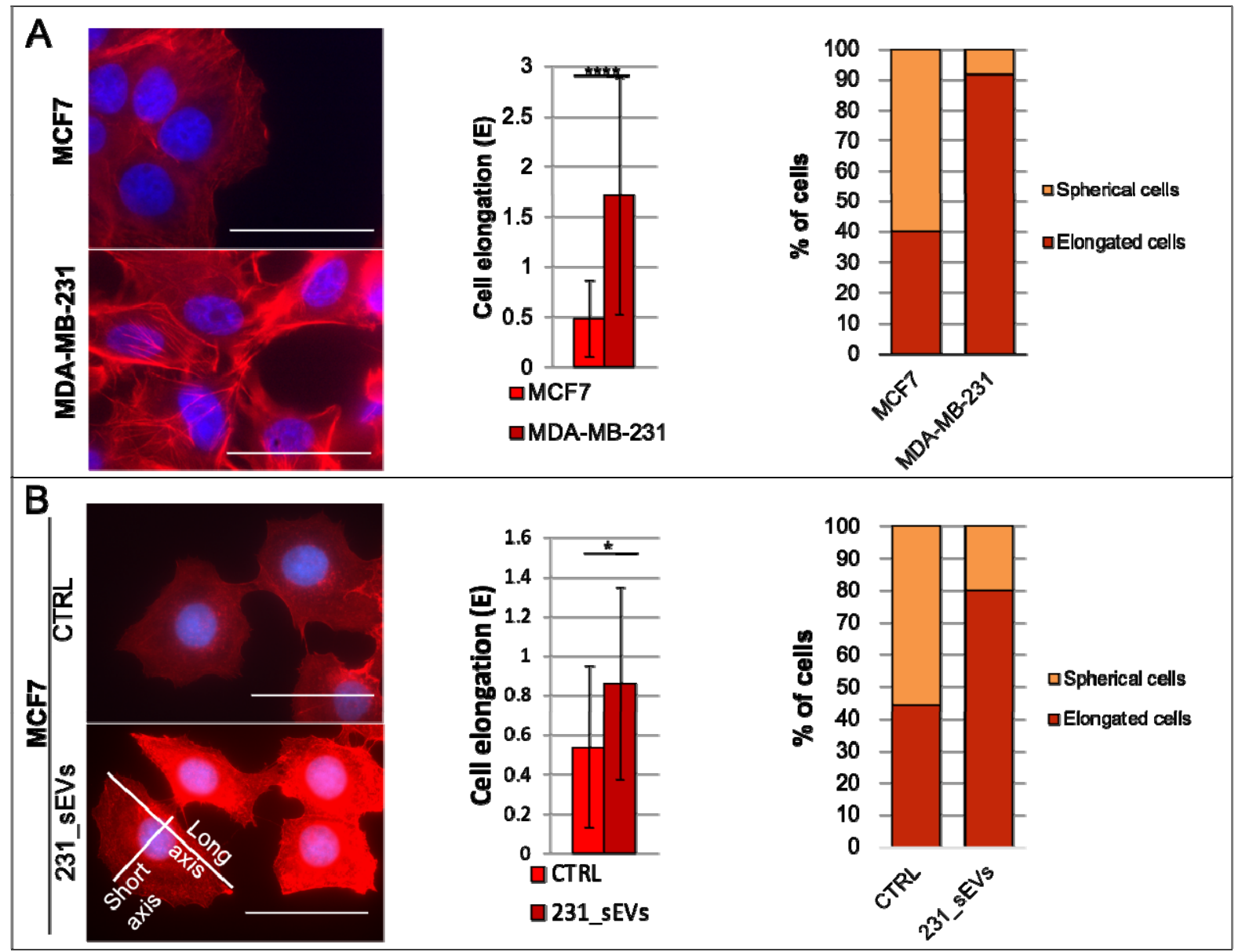

Figure 5. Effects of 231_sEVs on cell elongation of MCF7 cells. Representative epifluorescence images on left and histograms on right, respectively, showing the cell elongation and percentage of elongated cells in (a) MCF7 and MDAMB-231 cells and in (b) MCF7 cells treated with 231_sEVs, in relation to their relative control. Data are expressed as mean \pm SD. Significance of data differences was established via two-tailed Student's t-test. Scale bar indicates $50 \mu \mathrm{m}$.

To further investigate the small EV-induced transformations, we also investigated the nuclear morphology of the different cells. Significant smaller nuclear area and lower nuclear circularity were observed in MDAMB-231 with respect to MCF7 cells, as shown in Figure 6a ( $n=525$ MDA-MB-231 cells and $n=744$ MCF7 cells). Similarly, MCF7 cells incubated with 231_sEVs show a significant reduction in nuclear size and circularity, when compared with the control (Figure 6b; $\mathrm{n}=744$ MCF7 CTRL cells and $\mathrm{n}=712$ 231_sEVstreated MCF7 cells). Therefore, the activity of vesicles derived from MDA-MB-231 makes nuclear morphology of the MCF7 cells similar to that of MDA-MB-231 cells. 

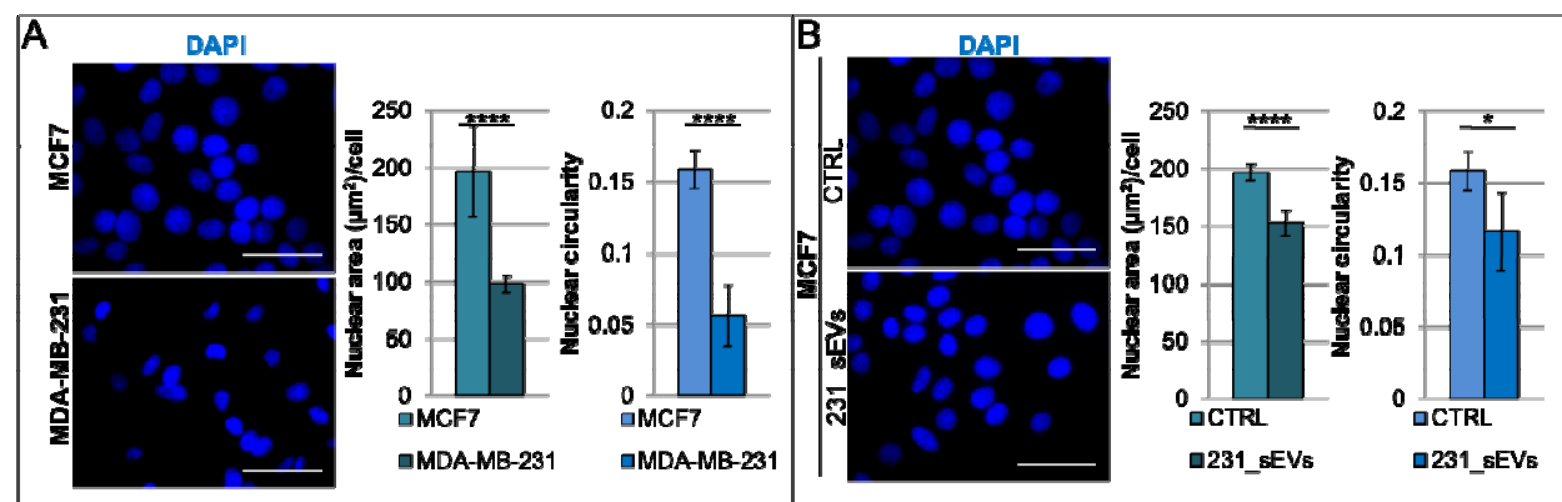

Figure 6. Effects of 231_sEVs on nuclear morphology of MCF7 cells. Representative epifluorescence images on left and histograms on right, respectively, showing the nuclear area and nuclear circularity in (a) MCF7 and MDA-MB-231 cells and in (b) MCF7 cells treated with 231_sEVs, in relation to their relative control. Data are expressed as mean \pm SD. Significance of data differences was established via two-tailed Student's t-test. Scale bar indicates $50 \mu \mathrm{m}$.

Lastly, we examinated both the density and size of FAs of the different cells by staining the Vinculin and the phosphorylated-focal adhesion kinase (pFAK).

When compared with MCF7, MDA-MB-231 cells show significantly lower density of FAs, as inferred from both the Vinculin and pFAK TIRF images, and significant lower adhesion size, as detected via the pFAK signal (Figure 7a-b; $\mathrm{n}=47$ and $\mathrm{n}=35$ MDA-MB-231 cells for Vinculin and $\mathrm{pFAK}$, respectively; $\mathrm{n}=25$ and $\mathrm{n}=29$ MCF7 cells for Vinculin and pFAK, respectively). On the contrary, MCF7 cells treated with 231_sEV show a significantly higher density and size of focal adhesions, when compared to the control (Figure 7c-d; $\mathrm{n}$ $=25$ and $n=29$ MCF7 CTRL cells for Vinculin and pFAK, respectively; $n=26$ and $n=23$ 231_sEVstreated MCF7 cells for Vinculin and pFAK, respectively). Therefore, in contrast to the cytoskeleton and morphology results (Figure 4-5), 231_sEVs appear to provide MCF7 cells an adhesion phenotype different from the donor MDA-MB-231 cells. Specifically, they promote an increase of FA activity. 


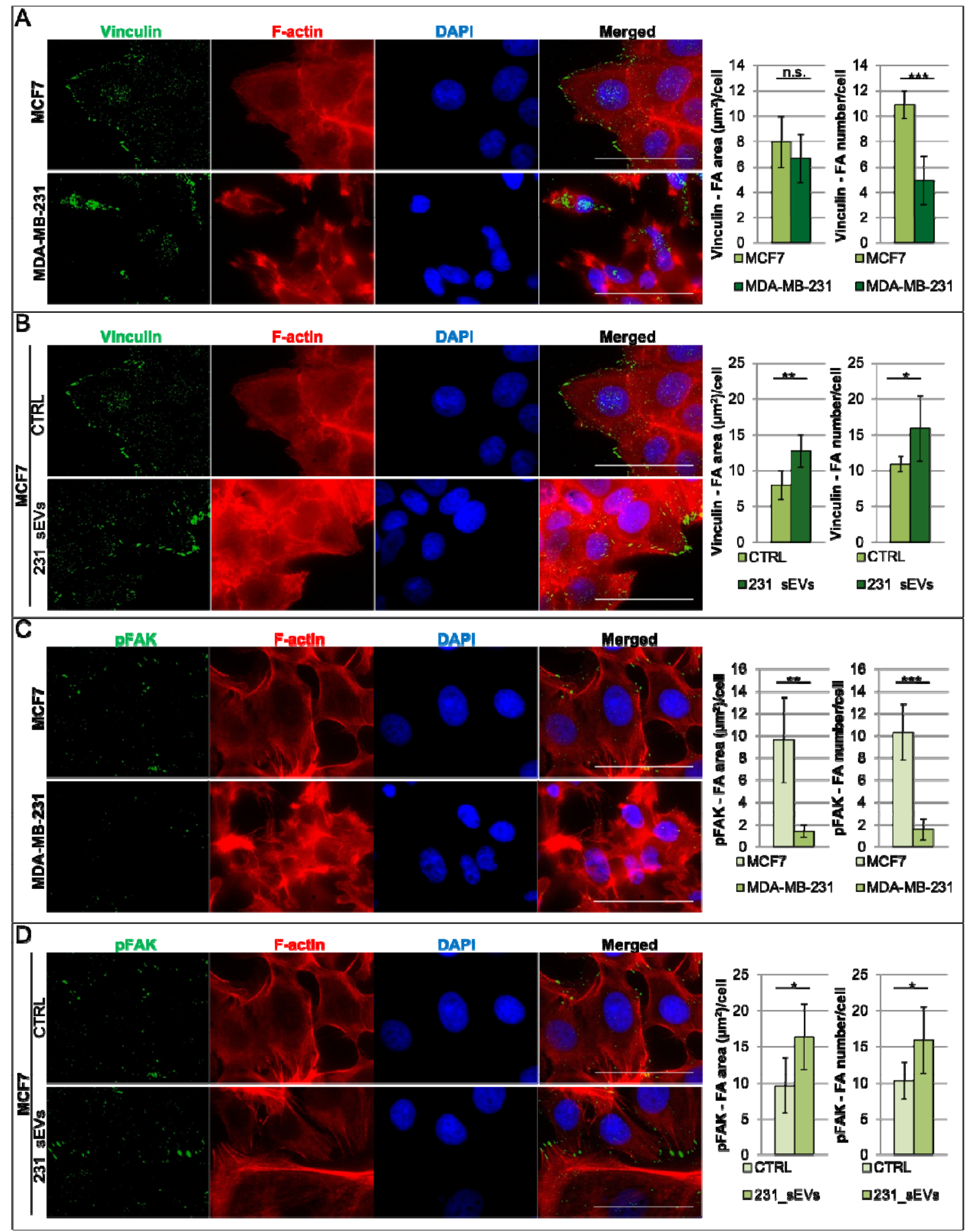

Figure 7. Effects of small EVs derived from MDA-MB-231 on focal adhesions of MCF7 cells. Representative TIRF (Vinculin and pFAK) and epifluorescence (F-actin and DAPI) images on left and relative histograms on right, respectively, showing the area, density, and activity of FAs in (a-c) MCF7 and MDA-MB-231 cells and in (b-d) MCF7 cells treated with 231_sEVs, in relation to their negative control. Data are expressed as mean \pm SD. Significance of data differences was established via two-tailed Student's t-test. Scale bar indicates $50 \mu \mathrm{m}$. N.s. indicates not significant. 


\subsubsection{Small Extracellular Vesicles derived from MDA-MB-231 induce Yap activation in MCF7 cells}

We then wondered if the phenotypic rearrangement previously observed could match with any variations in Yap activity. Yes-associated protein (YAP), a transcriptional co-activator negatively regulated from the Hippo pathway, is known to play an important role in cellular biomechanical modulation and, in particular, in regulation of the acto-myosin network (Qiao et al., 2017)(Dobrokhotov et al., 2018) and focal adhesions (Nardone et al., 2017). Yap is an oncoprotein and abnormally accumulation of nuclear YAP has been observed in many types of cancer, including breast cancer (Qiao et al., 2017)(Dobrokhotov et al., 2018). In particular, the increase in Yap activity can drive (i) the lack of contact/density-dependent inhibition of growth (Dasgupta \& McCollum, 2019), (ii) an increase in cellular motility, invasion and metastasis (Z. Wang et al., 2014), (iii) a marked increase in FA formation (Nardone et al., 2017)(Shen et al., 2018), and (iv) the promotion of FAK phosphorylation (Shen et al., 2018).

Therefore, we investigated via RT-qPCR the expression level of three Yap downstream genes, CTGF, CYR61, and ANKRD1, as a readout of Yap activation/activity. In agreement with literature (Shen et al., 2018), we found that Yap is minimally active in MCF7 cells, whereas Yap downstream genes are overexpressed in MDA-MB-231 cells (Figure 8a). Interestingly, a not significant and a significant increase in CTGF and ANKRD1 expression, respectively, was reproducibly observed in MCF7 cells upon 231_sEV treatment (Figure 8b). This result could suggest a correlation between the 231_sEV addition and an enhanced Yap activity in MCF7 cells; these variations in Yap activity, which deserves further analysis, suggest the involvement of a pathway regulated and regulator of biomechanics as proof of the cell phenotypic changes observed above in MCF7 cells treated with 231_sEVs.

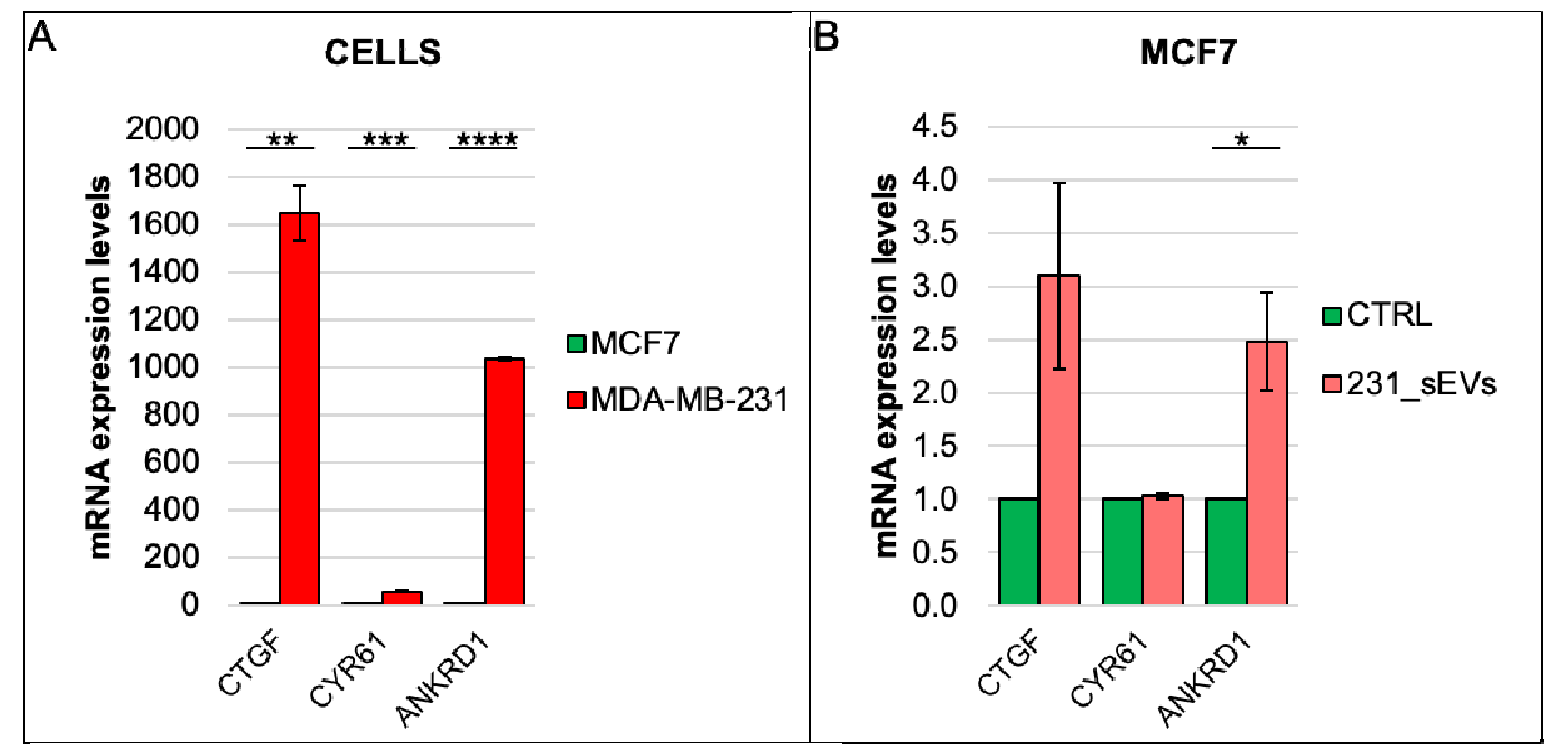

Figure 8. Effects of small EVs derived from MDA-MB-231 on Yap downstream gene expression of MCF7 cells. Expression of Yap target genes measured by RT-qPCR in a) MCF7 and MDA-MB-231 cells and in b) MCF7 cells 
treated with 231_sEVs, in relation to their negative control. Data normalized on histone H3. Data are expressed as mean \pm SD. Significance of data differences was established via two-tailed Student's t-test. N.s. indicates not significant.

\section{DISCUSSION}

Despite the constant progress in breast cancer field, the development of metastases in TNBC remains a highly complex and poorly understood process with a relatively poor outcome (Al-Mahmood et al., 2018). It is known that more deformable and softer cancer cells exhibit greater metastatic ability (Rudzka et al., 2019). On the other side, extracellular vesicles released by triple-negative breast cancer cells have been found to transfer functional cargos to target cells promoting cell proliferation, tumor growth, cancer cell invasion, and metastasis (Green et al., 2015). In light of that, we were interested in highlighting the mechanisms through which EVs from TNBC induce or regulate the metastatic processes, and in particular how do they influence/modulate the biomechanics of the recipient cells. Sparse information in this direction is coming from the recent literature: Sung and colleagues demonstrated that the secretion of small extracellular vesicles is required for directionally persistent and efficient in vivo movement of cancer cells (Sung et al., 2015); small EVs secreted by mesenchymal stromal/stem cell-derived adipocytes can promote breast cancer cell growth by activating Hippo signaling pathway (S. Wang et al., 2019); breast cancer-derived EVs were seen to contribute to metastasis by altering the tissue mechanics of distant organs to support tumor cell invasion and seeding (Pokharel et al., 2016)(Barenholz-Cohen et al., 2020); moreover, single EV characterization studies reported the conservation of biomechanical traits of EVs with respect to their cells of origin (softer EVs were found to be secreted by softer cells) (LeClaire et al., 2021; Ye et al., 2021). In the present study we showed for the first time that beside preserving the biophysical properties of the donor cells, as shown by (LeClaire et al., 2021 Ye et al., 2021), the extracellular vesicles are able to transfer these features directly to the target cells. In detail, we demonstrated that TNBC-derived small EVs directly modify the biomechanical phenotype of the non-invasive MCF7 target cells, by affecting cellular stiffness, cytoskeleton, nuclear and cellular morphology, adhesion, and Yap downstream gene expression variations. Our results evidenced that the MCF7 cells treated with 231_sEVs adapt their stiffness, cellular and nuclear morphology in the likeness of the MDA-MB-231 cells. Yet, their adhesion properties are different. Interestingly, we observed an increase in FA number, density, and activity in 231_sEVs treated MCF7 cells with respect to the EVs progenitor cells, which might be a direct consequence of small EV uptake. It has been shown from recent studies that the integrin beta 3, ITGB3, which plays an essential role in cancer metastasis in MDA-MB-231, and its interaction and activation of focal adhesion kinase (FAK has a fundamental role in extracellular vesicle biogenesis and uptake in breast cancer cells (Altei et al., 2020)(Fuentes et al., 2020). According to these works, ITGB3 is required both as small EVs receptor (by interacting with heparan sulfate proteoglycans (HSPGs)) and for intracellular FAK activation to promote vesicles endocytosis. These findings are well fitting with our observations. Although FAs and FAK in breast malignancy metastasis have been widely studied, it is not perfectly clear yet how FAs are regulated in tumors and many data present in the literature on FAs size, number, and activity in cancer cell lines are quite scattered. Direct correlation 
between metastatic/aggressive potential of cancer cells and large number/small size of focal adhesion complexes were demonstrated in some other works (Rönnlund et al., 2013)(Gad et al., 2012)(Kraning-Rush et al., 2012). In contrast, other studies showed that invasive cells are characterized by large dynamic adhesion sites with an increased activation of the phosphorylated-focal adhesion kinase (pFAK) (Peschetola et al., 2013)(Tavares et al., 2017). pFAK, by recruiting other signaling molecules, promotes in turn the assembly of focal adhesion complexes (Shen et al., 2018). This protein has been observed to have an oncogenic role in many types of human cancers (Shen et al., 2018), including metastasis and poor prognosis in breast cancer (M. Luo \& Guan, 2010). Our FA results are consistent with the work of (Peschetola et al., 2013)(Tavares et al., 2017), pointing to a correlation of invasiveness with large dynamic adhesion sites and an increased activation of pFAK.

Moreover, we also highlighted a high expression of Yap downstream genes in the 231_sEVs treated MCF7 cells, similar to the case of MDA-MB-231 cells, and its correlation with high levels of filamentous actin, as well as with a marked increase in FA formation/promotion of FAK phosphorylation. Also in the case of the oncoprotein Yap, conflicting results on the mechanisms through which it regulates actin cytoskeleton polymerization and FAs were reported. Concerning the actin regulation, in the study of Qiao et al. the Yap activation in human gastric cancer cells is shown to drive an actin depolymerization with consequent cell softening (Qiao et al., 2017), while in the study of Nardone et al. it promotes in adipose tissue-derived mesenchymal stem cells the formation of stress fibers with consequent cell stiffening (Nardone et al., 2017). Such opposite results might be related to the way Yap regulates the acto-myosin system, as it promotes the expression of both a RhoA activator (ARHGEF17) and RhoA inhibitors (ARHGAP18/29) (Dobrokhotov et al., 2018). Concerning FAs modulation, Shen et al. observed that YAP promotes focal adhesion dynamics in breast cancer cells (MCF7 and MDA-MB-231), but they did not report any significant actin changes upon Yap overexpression or silencing (Shen et al., 2018). Our findings support both the results of Nardone et al. and Shen et al. (Nardone et al., 2017)(Shen et al., 2018).

In conclusion, we showed that TNBC-derived small EVs alter the biomechanical response of recipient cells. Our results admit two possible explanations of the mechanism through which TNBC-derived small EVs can influence cell biomechanics. The first possible route is based on the hypothesis that the small EV uptake occurs through FAs, which being subject to changes, then, consequently modulate Yap activity, cytoskeleton, nuclear/cell morphology, and biomechanics of target cells. Alternatively, TNBC-derived small EVs could directly cause an increase in Yap activity, which in turn leads to cytoskeleton, nuclear/cell morphology, adhesion and, finally, biomechanical rearrangements in MCF7 cells. Further studies (as proteomic and/or RNA analyses) will be needed to clarify this point, which falls outside the aim of the present work.

We believe that testing the biomechanical properties of both cells and tissues after EV treatment might represent a new approach capable of assessing the activity of EVs and the cargo release mechanisms; this 
assay could be potentially applied not only to other types of cancers but also to other diseases, where biomechanical properties can have prominent roles.

\section{ACKNOWLEDGMENTS}

The authors wish to thank the Structural Biology Laboratory of Elettra-Sincrotrone Trieste S.C.p.A for the instrumentation and the continuous support. The work was supported by Università degli Studi di Trieste, Area Science Park, European Regional Development Fund and Interreg V-A Italia - Austria 2014-2020 (EXOTHERA- ITAT1036), AIRC (IG 21803 to L.Co.) and by Regione Friuli Venezia Giulia (legge regionale 17/2004, BioMec project).

\section{CONFLICT OF INTEREST}

The authors declare no conflicts of interest.

\section{REFERENCES}

Al-Mahmood, S., Sapiezynski, J., Garbuzenko, O. B., \& Minko, T. (2018). Metastatic and triplenegative breast cancer: challenges and treatment options. In Drug Delivery and Translational Research (Vol. 8, Issue 5, pp. 1483-1507). https://doi.org/10.1007/s13346-018-0551-3

Alibert, C., Goud, B., \& Manneville, J. B. (2017). Are cancer cells really softer than normal cells? In Biology of the Cell (Vol. 109, Issue 5, pp. 167-189). https://doi.org/10.1111/boc.201600078

Altei, W. F., Pachane, B. C., Dos Santos, P. K., Ribeiro, L. N. M., Sung, B. H., Weaver, A. M., \& Selistre-De-Araújo, H. S. (2020). Inhibition of $\alpha v \beta 3$ integrin impairs adhesion and uptake of tumor-derived small extracellular vesicles. Cell Communication and Signaling, 18(1). https://doi.org/10.1186/s12964-020-00630-w

Bahreyni, A., Mohamud, Y., \& Luo, H. (2020). Emerging nanomedicines for effective breast cancer immunotherapy. Journal of Nanobiotechnology, 18(1), 180. https://doi.org/10.1186/s12951020-00741-z

Bao, S., Hu, T., Liu, J., Su, J., Sun, J., Ming, Y., Li, J., Wu, N., Chen, H., \& Zhou, M. (2021). Genomic instability-derived plasma extracellular vesicle-microRNA signature as a minimally invasive predictor of risk and unfavorable prognosis in breast cancer. Journal of Nanobiotechnology, 19(1), 22. https://doi.org/10.1186/s12951-020-00767-3

Barenholz-Cohen, T., Merkher, Y., Haj, J., Shechter, D., Kirchmeier, D., Shaked, Y., \& Weihs, D. (2020). Lung mechanics modifications facilitating metastasis are mediated in part by breast cancer-derived extracellular vesicles. International Journal of Cancer, 147(10), 2924-2933. https://doi.org/10.1002/ijc.33229

Bebelman, M. P., Smit, M. J., Pegtel, D. M., \& Baglio, S. R. (2018). Biogenesis and function of 
extracellular vesicles in cancer. In Pharmacology and Therapeutics (Vol. 188, pp. 1-11). https://doi.org/10.1016/j.pharmthera.2018.02.013

Becker, A., Thakur, B. K., Weiss, J. M., Kim, H. S., Peinado, H., \& Lyden, D. (2016). Extracellular Vesicles in Cancer: Cell-to-Cell Mediators of Metastasis. In Cancer Cell (Vol. 30, Issue 6, pp. 836-848). https://doi.org/10.1016/j.ccell.2016.10.009

Boukouris, S., \& Mathivanan, S. (2015). Exosomes in bodily fluids are a highly stable resource of disease biomarkers. In Proteomics - Clinical Applications (Vol. 9, Issues 3-4, pp. 358-367). https://doi.org/10.1002/prca.201400114

Cai, H., Reinisch, K., \& Ferro-Novick, S. (2007). Coats, Tethers, Rabs, and SNAREs Work Together to Mediate the Intracellular Destination of a Transport Vesicle. In Developmental Cell (Vol. 12, Issue 5, pp. 671-682). https://doi.org/10.1016/j.devcel.2007.04.005

Chen, I. H., Xue, L., Hsu, C. C., Paez, J. S. P., Panb, L., Andaluz, H., Wendt, M. K., Iliuk, A. B., Zhu, J. K., \& Tao, W. A. (2017). Phosphoproteins in extracellular vesicles as candidate markers for breast cancer. Proceedings of the National Academy of Sciences of the United States of America, 114(12), 3175-3180. https://doi.org/10.1073/pnas.1618088114

Chiotaki, R., Polioudaki, H., \& Theodoropoulos, P. A. (2014). Differential nuclear shape dynamics of invasive andnon-invasive breast cancer cells are associated with actin cytoskeleton organization and stability. Biochemistry and Cell Biology, 92(4), 287-295. https://doi.org/10.1139/bcb-2013-0120

Dasgupta, I., \& McCollum, D. (2019). Control of cellular responses to mechanical cues through YAP/TAZ regulation. In Journal of Biological Chemistry (Vol. 294, Issue 46, pp. 17693 17706). https://doi.org/10.1074/jbc.REV119.007963

Dobrokhotov, O., Samsonov, M., Sokabe, M., \& Hirata, H. (2018). Mechanoregulation and pathology of YAP/TAZ via Hippo and non $\square$ Hippo mechanisms. Clinical and Translational Medicine, 7(1). https://doi.org/10.1186/s40169-018-0202-9

Dogterom, M., \& Koenderink, G. H. (2019). Actin-microtubule crosstalk in cell biology. Nature Reviews Molecular Cell Biology, 20(1), 38-54. https://doi.org/10.1038/s41580-018-0067-1

Etienne-Manneville, S. (2004). Actin and microtubules in cell motility: Which one is in control? In Traffic (Vol. 5, Issue 7, pp. 470-477). https://doi.org/10.1111/j.1600-0854.2004.00196.x Fischer, T., Hayn, A., \& Mierke, C. T. (2020). Effect of Nuclear Stiffness on Cell Mechanics and Migration of Human Breast Cancer Cells. Frontiers in Cell and Developmental Biology, 8. https://doi.org/10.3389/fcell.2020.00393

Fritsch, A., Höckel, M., Kiessling, T., Nnetu, K. D., Wetzel, F., Zink, M., \& Käs, J. A. (2010). Are biomechanical changes necessary for tumour progression? In Nature Physics (Vol. 6, Issue 10, 
pp. 730-732). https://doi.org/10.1038/nphys 1800

Fuentes, P., Sesé, M., Guijarro, P. J., Emperador, M., Sánchez-Redondo, S., Peinado, H., Hümmer, S., \& Ramón y. Cajal, S. (2020). ITGB3-mediated uptake of small extracellular vesicles facilitates intercellular communication in breast cancer cells. Nature Communications, 11(1). https://doi.org/10.1038/s41467-020-18081-9

Gad, A. K. B., Rönnlund, D., Spaar, A., Savchenko, A. A., Petranyi, G., Blom, H., Szekely, L., Widengren, J., \& Aspenström, P. (2012). Rho GTPases link cellular contractile force to the density and distribution of nanoscale adhesions. The FASEB Journal, 26(6), 2374-2382. https://doi.org/10.1096/fj.11-195800

Gest, C., Joimel, U., Huang, L., Pritchard, L. L., Petit, A., Dulong, C., Buquet, C., Hu, C. Q., Mirshahi, P., Laurent, M., Fauvel-Lafève, F., Cazin, L., Vannier, J. P., Lu, H., Soria, J., Li, H., Varin, R., \& Soria, C. (2013). Rac3 induces a molecular pathway triggering breast cancer cell aggressiveness: Differences in MDA-MB-231 and MCF-7 breast cancer cell lines. BMC Cancer, 13. https://doi.org/10.1186/1471-2407-13-63

Goh, C. Y., Wyse, C., Ho, M., O’Beirne, E., Howard, J., Lindsay, S., Kelly, P., Higgins, M., \& McCann, A. (2020). Exosomes in triple negative breast cancer: Garbage disposals or Trojan horses? In Cancer Letters (Vol. 473, pp. 90-97). https://doi.org/10.1016/j.canlet.2019.12.046

Green, T. M., Alpaugh, M. L., Barsky, S. H., Rappa, G., \& Lorico, A. (2015). Breast cancer-derived extracellular vesicles: Characterization and contribution to the metastatic phenotype. In BioMed Research International (Vol. 2015). https://doi.org/10.1155/2015/634865

Grimm, K. B., Oberleithner, H., \& Fels, J. (2014). Fixed endothelial cells exhibit physiologically relevant nanomechanics of the cortical actin web. Nanotechnology, 25(21), 215101. https://doi.org/10.1088/0957-4484/25/21/215101

H., F., Zarghi, A., Kobarfard, F., Zendehdel, R., Nakhjavani, M., Arfaiee, S., Zebardast, T., Mohebi, S., Anjidani, N., Ashtarinezhad, A., \& Shoeibi, S. (2011). Remarks in Successful Cellular Investigations for Fighting Breast Cancer Using Novel Synthetic Compounds. In Breast Cancer - Focusing Tumor Microenvironment, Stem cells and Metastasis. https://doi.org/10.5772/23005

Harris, D. A., Patel, S. H., Gucek, M., Hendrix, A., Westbroek, W., \& Taraska, J. W. (2015). Exosomes released from breast cancer carcinomas stimulate cell movement. PLoS ONE, 10(3). https://doi.org/10.1371/journal.pone.0117495

Hermanowicz, P., Sarna, M., Burda, K., \& Gabryś, H. (2014). AtomicJ: an open source software for analysis of force curves. The Review of Scientific Instruments, 85(6), 63703. https://doi.org/10.1063/1.4881683 
Islam, T., \& Resat, H. (2017). Quantitative investigation of MDA-MB-231 breast cancer cell motility: Dependence on epidermal growth factor concentration and its gradient. Molecular BioSystems, 13(10), 2069-2082. https://doi.org/10.1039/c7mb00390k

Jhan, J. R., \& Andrechek, E. R. (2017). Triple-negative breast cancer and the potential for targeted therapy. Pharmacogenomics, 18(17), 1595-1609. https://doi.org/10.2217/pgs-2017-0117

Kalluri, R., \& LeBleu, V. S. (2020). The biology, function, and biomedical applications of exosomes. In Science (Vol. 367, Issue 6478). https://doi.org/10.1126/science.aau6977

Kim, S.-O., Kim, J., Okajima, T., \& Cho, N.-J. (2017). Mechanical properties of paraformaldehydetreated individual cells investigated by atomic force microscopy and scanning ion conductance microscopy. Nano Convergence, 4(1), 5. https://doi.org/10.1186/s40580-017-0099-9

Kraning-Rush, C. M., Califano, J. P., \& Reinhart-King, C. A. (2012). Cellular traction stresses increase with increasing metastatic potential. PLOS ONE, 7(2). https://doi.org/10.1371/journal.pone.0032572

LeClaire, M., Wohlschlegel, J. A., Chang, H., Wadehra, M., Yu, W., Rao, J., Elashoff, D., Gimzewski, J. K., \& Sharma, S. (2021). Nanoscale Extracellular Vesicles Carry the Mechanobiology Signatures of Breast Cancer Cells. ACS Applied Nano Materials, 4(9), 98769885. https://doi.org/10.1021/acsanm.1c02299

Lee, G. Y. H., \& Lim, C. T. (2007). Biomechanics approaches to studying human diseases. Trends in Biotechnology, 25(3), 111-118. https://doi.org/10.1016/j.tibtech.2007.01.005

Lekka, M. (2016). Discrimination Between Normal and Cancerous Cells Using AFM. BioNanoScience, 6(1), 65-80. https://doi.org/10.1007/s 12668-016-0191-3

Lüchtefeld, I., Bartolozzi, A., Mejía Morales, J., Dobre, O., Basso, M., Zambelli, T., \& Vassalli, M. (2020). Elasticity spectra as a tool to investigate actin cortex mechanics. Journal of Nanobiotechnology, 18(1), 147. https://doi.org/10.1186/s12951-020-00706-2

Luo, M., \& Guan, J. L. (2010). Focal adhesion kinase: A prominent determinant in breast cancer initiation, progression and metastasis. In Cancer Letters (Vol. 289, Issue 2, pp. 127-139). https://doi.org/10.1016/j.canlet.2009.07.005

Luo, Q., Kuang, D., Zhang, B., \& Song, G. (2016). Cell stiffness determined by atomic force microscopy and its correlation with cell motility. In Biochimica et Biophysica Acta - General Subjects (Vol. 1860, Issue 9, pp. 1953-1960). https://doi.org/10.1016/j.bbagen.2016.06.010

Maacha, S., Bhat, A. A., Jimenez, L., Raza, A., Haris, M., Uddin, S., \& Grivel, J. C. (2019). Extracellular vesicles-mediated intercellular communication: Roles in the tumor microenvironment and anti-cancer drug resistance. In Molecular Cancer (Vol. 18, Issue 1). https://doi.org/10.1186/s12943-019-0965-7 
Maia, J., Caja, S., Strano Moraes, M. C., Couto, N., \& Costa-Silva, B. (2018). Exosome-based cellcell communication in the tumor microenvironment. In Frontiers in Cell and Developmental Biology (Vol. 6, Issue FEB). https://doi.org/10.3389/fcell.2018.00018

Martin, T., Ye, L., Sanders, A., Lane, J., \& Jiang, W. (2014). Cancer Invasion and Metastasis: Molecular and Cellular Perspective. In Metastatic Cancer: Clinical and Biological Perspectives (Vol. 9).

Momenimovahed, Z., \& Salehiniya, H. (2019). Epidemiological characteristics of and risk factors for breast cancer in the world. In Breast Cancer: Targets and Therapy (Vol. 11, pp. 151-164). https://doi.org/10.2147/BCTT.S176070

Nakashoji, A., Matsui, A., Nagayama, A., Iwata, Y., Sasahara, M., \& Murata, Y. (2017). Clinical predictors of pathological complete response to neoadjuvant chemotherapy in triple $\square$ negative breast cancer. Oncology Letters, 14(4), 4135-4141. https://doi.org/10.3892/ol.2017.6692

Nardone, G., Oliver-De La Cruz, J., Vrbsky, J., Martini, C., Pribyl, J., Skládal, P., Pešl, M., Caluori, G., Pagliari, S., Martino, F., Maceckova, Z., Hajduch, M., Sanz-Garcia, A., Pugno, N. M., Stokin, G. B., \& Forte, G. (2017). YAP regulates cell mechanics by controlling focal adhesion assembly. Nature Communications, 8. https://doi.org/10.1038/ncomms15321

Nečas, D., \& Klapetek, P. (2012). Gwyddion: an open-source software for SPM data analysis. Central European Journal of Physics, 10(1), 181-188. https://doi.org/10.2478/s11534-0110096-2

Ozawa, P. M. M., Alkhilaiwi, F., Cavalli, I. J., Malheiros, D., de Souza Fonseca Ribeiro, E. M., \& Cavalli, L. R. (2018). Extracellular vesicles from triple-negative breast cancer cells promote proliferation and drug resistance in non-tumorigenic breast cells. Breast Cancer Research and Treatment, 172(3), 713-723. https://doi.org/10.1007/s10549-018-4925-5

Parisse, P., Rago, I., Ulloa Severino, L., Perissinotto, F., Ambrosetti, E., Paoletti, P., Ricci, M., Beltrami, A. P., Cesselli, D., \& Casalis, L. (2017). Atomic force microscopy analysis of extracellular vesicles. European Biophysics Journal $\square:$ EBJ, 46(8), 813-820. https://doi.org/10.1007/s00249-017-1252-4

Peng, J., Wang, W., Hua, S., \& Liu, L. (2018). Roles of Extracellular Vesicles in Metastatic Breast Cancer. In Breast Cancer: Basic and Clinical Research (Vol. 12). https://doi.org/10.1177/1178223418767666

Peschetola, V., Laurent, V. M., Duperray, A., Michel, R., Ambrosi, D., Preziosi, L., \& Verdier, C. (2013). Time-dependent traction force microscopy for cancer cells as a measure of invasiveness. Cytoskeleton, 70(4), 201-214. https://doi.org/10.1002/cm.21100

Pokharel, D., Wijesinghe, P., Oenarto, V., Lu, J. F., Sampson, D. D., Kennedy, B. F., Wallace, V. 
P., \& Bebawy, M. (2016). Deciphering Cell-to-Cell Communication in Acquisition of Cancer Traits: Extracellular Membrane Vesicles Are Regulators of Tissue Biomechanics. Omics $\square: A$ Journal of Integrative Biology, 20(8), 462-469. https://doi.org/10.1089/omi.2016.0072

Qiao, Y., Chen, J., Lim, Y. B., Finch-Edmondson, M. L., Seshachalam, V. P., Qin, L., Jiang, T., Low, B. C., Singh, H., Lim, C. T., \& Sudol, M. (2017). YAP Regulates Actin Dynamics through ARHGAP29 and Promotes Metastasis. Cell Reports, 19(8), 1495-1502. https://doi.org/10.1016/j.celrep.2017.04.075

Rönnlund, D., Gad, A. K. B., Blom, H., Aspenström, P., \& Widengren, J. (2013). Spatial organization of proteins in metastasizing cells. Cytometry Part A, 83(9), 855-865. https://doi.org/10.1002/cyto.a.22304

Rudzka, D. A., Spennati, G., McGarry, D. J., Chim, Y. H., Neilson, M., Ptak, A., Munro, J., Kalna, G., Hedley, A., Moralli, D., Green, C., Mason, S., Blyth, K., Mullin, M., Yin, H., \& Olson, M. F. (2019). Migration through physical constraints is enabled by MAPK-induced cell softening via actin cytoskeleton re-organization. Journal of Cell Science, 132(11). https://doi.org/10.1242/jcs.224071

Senigagliesi, B., Penzo, C., Severino, L. U., Maraspini, R., Petrosino, S., Morales-Navarrete, H., Pobega, E., Ambrosetti, E., Parisse, P., Pegoraro, S., Manfioletti, G., Casalis, L., \& Sgarra, R. (2019). The high mobility group A1 (HMGA1) chromatin architectural factor modulates nuclear stiffness in breast cancer cells. International Journal of Molecular Sciences, 20(11). https://doi.org/10.3390/ijms20112733

Shang, M., Chang, C., Pei, Y., Guan, Y., Chang, J., \& Li, H. H. (2018). Potential management of circulating tumor DNA as a biomarker in triple-negative breast cancer. In Journal of Cancer (Vol. 9, Issue 24, pp. 4627-4634). https://doi.org/10.7150/jca.28458

Sharma, S., Rasool, H. I., Palanisamy, V., Mathisen, C., Schmidt, M., Wong, D. T., \& Gimzewski, J. K. (2010). Structural-mechanical characterization of nanoparticle exosomes in human saliva, using correlative AFM, FESEM, and force spectroscopy. ACS Nano, 4(4), 1921-1926. https://doi.org/10.1021/nn901824n

Shen, J., Cao, B., Wang, Y., Ma, C., Zeng, Z., Liu, L., Li, X., Tao, D., Gong, J., \& Xie, D. (2018). Hippo component YAP promotes focal adhesion and tumour aggressiveness via transcriptionally activating THBS1/FAK signalling in breast cancer. Journal of Experimental and Clinical Cancer Research, 37(1). https://doi.org/10.1186/s13046-018-0850-z

Shibue, T., \& Weinberg, R. A. (2017). EMT, CSCs, and drug resistance: The mechanistic link and clinical implications. In Nature Reviews Clinical Oncology (Vol. 14, Issue 10, pp. 611-629). https://doi.org/10.1038/nrclinonc.2017.44 
Stylianou, A., Gkretsi, V., \& Stylianopoulos, T. (2018). Transforming growth factor- $\beta$ modulates pancreatic cancer associated fibroblasts cell shape, stiffness and invasion. Biochimica et Biophysica Acta. General Subjects, 1862(7), 1537-1546. https://doi.org/10.1016/j.bbagen.2018.02.009

Sung, B. H., Ketova, T., Hoshino, D., Zijlstra, A., \& Weaver, A. M. (2015). Directional cell movement through tissues is controlled by exosome secretion. Nature Communications, 6 . https://doi.org/10.1038/ncomms8164

Tavares, S., Vieira, A. F., Taubenberger, A. V., Araújo, M., Martins, N. P., Brás-Pereira, C., Polónia, A., Herbig, M., Barreto, C., Otto, O., Cardoso, J., Pereira-Leal, J. B., Guck, J., Paredes, J., \& Janody, F. (2017). Actin stress fiber organization promotes cell stiffening and proliferation of pre-invasive breast cancer cells. Nature Communications, 8 . https://doi.org/10.1038/ncomms 15237

Thery, C., Witwer, K., Aikawa, E., Jose Alcaraz, M., Anderson, J., Andriantsitohaina, R., Antoniou, A., Arab, T., Archer, F., Atkin-Smith, G., Ayre, D., Bach, J.-M., Bachurski, D., Baharvand, H., Balaj, L., Baldacchino, S., Bauer, N., Baxter, A., Bebawy, M., ... Helena Vasconcelos, M. (2018). Minimal information for studies of extracellular vesicles 2018 (MISEV2018). Journal of Extracellular Vesicles, 7:1535750, 1-47.

Tschuschke, M., Kocherova, I., Bryja, A., Mozdziak, P., Angelova Volponi, A., Janowicz, K., Sibiak, R., Piotrowska-Kempisty, H., Iżycki, D., Bukowska, D., Antosik, P., Shibli, J. A., Dyszkiewicz-Konwińska, M., \& Kempisty, B. (2020). Inclusion Biogenesis, Methods of Isolation and Clinical Application of Human Cellular Exosomes. Journal of Clinical Medicine, 9(2), 436. https://doi.org/10.3390/jcm9020436

Wang, S., Su, X., Xu, M., Xiao, X., Li, X., Li, H., Keating, A., \& Zhao, R. C. (2019). Exosomes secreted by mesenchymal stromal/stem cell-derived adipocytes promote breast cancer cell growth via activation of Hippo signaling pathway. Stem Cell Research and Therapy, 10(1). https://doi.org/10.1186/s13287-019-1220-2

Wang, Z., Wu, Y., Wang, H., Zhang, Y., Mei, L., Fang, X., Zhang, X., Zhang, F., Chen, H., Liu, Y., Jiang, Y., Sun, S., Zheng, Y., Li, N., \& Huang, L. (2014). Interplay of mevalonate and Hippo pathways regulates RHAMM transcription via YAP to modulate breast cancer cell motility. Proceedings of the National Academy of Sciences of the United States of America, 111(1). https://doi.org/10.1073/pnas.1319190110

Yao, X., Xie, R., Cao, Y., Tang, J., Men, Y., Peng, H., \& Yang, W. (2021). Simvastatin induced ferroptosis for triple-negative breast cancer therapy. Journal of Nanobiotechnology, 19(1), 311. https://doi.org/10.1186/s12951-021-01058-1 
Ye, S., Li, W., Wang, H., Zhu, L., Wang, C., \& Yang, Y. (2021). Quantitative Nanomechanical Analysis of Small Extracellular Vesicles for Tumor Malignancy Indication. Advanced Science (Weinheim, Baden-Wurttemberg, Germany), 8(18), e2100825.

https://doi.org/10.1002/advs.202100825

Yeo, W. (2015). Treatment horizons for triple-negative breast cancer. In Hong Kong Journal of Radiology (Vol. 18, Issue 2, pp. 111-118). https://doi.org/10.12809/hkjr1515321 